\title{
Conservation of Avian Diversity in India
}

\author{
Yahya HAS* \\ Aligarh Muslim University, India
}

*Corresponding author: Yahya HAS, Aligarh Muslim University, India, Tel:

\section{Editorial \\ Volume 1 Issue 1}

Received Date: February 05, 2018

Published Date: February 27, 2018

DOI: $10.23880 /$ izab-16000101

\section{Editorial}

Biodiversity conservation and climate change are most important contemporary issues. There is a pressing need to tackle these issues with utmost sincerity by biologists, nature conservanists, developmental agencies, religions clergies as well as politicians; otherwise with depleting biodiversity, that also impacts climate changes to larger extent, the mankind would jeopardize its own existence on this planet. Despite rapid decline and deterioration of their prime habitats, the avian diversity in India is quite rich. In this editorial note an overview of Indian ornithology is given in a view to priortise their conservion prospects.

Spirit of avian conservation and appreciation has been deeply rooted in Indian culture and ethos. Many ancient folklores, paintings, sculptures provide illustrative account how earlier people enjoyed watching, eating, taming and even worshiping birds. The Hindu mythology contains several revealing descriptions of birds' role in social, religious and cultural phenomena, so much so that Swan is considered as the carrier of Goddess of Education - the Saraswati, and the Owl is considered as the carrier of Goddess of Wealth - the Lakshmi; while Jatayu - the vulture played a key role in Ramayana. According to another Sanskrit story the crows look by one eye: This observation is quite apt from scientific as well as social point of views: as the crows have to tilt their head to see both sides view, and whenever they see food item they call other crows to join the feast, a social justification of seeing needs of other fellows with one eye - with equaity!.

Owing to a number of bio-geographical zones and diversified climatological regimes, India is bestowed with a very rich biodiversity and is rightly considered as one of the twelve Mega-biodiversity zones of the world. There are three distinct biodiversity hotspots in the country Western Ghats, Himalayas and North-east region. Comprising of 446 Important Bird Areas that supports occurrence of about 1300 species (out of 10065 species world over), the avian diversity of the country is also quite rich. Besides some ancient Indians rulers, such as King Ashoka, several Moghul Emperors kept a lively account of birds. Emperor Jahangir was more particularly very keen in documenting the nature and we have several accounts of his observations on birds and other animals in Tuzk-e-Jehangiri in which his courteous Ustad Manoor has painted a Dodo which was perhaps gifted to Jahangir by a visitor form Mauritius. While Salim Ali (The Moghul emperors of India as naturalists and sportsmen. 1927. JBNHS 32:34-63) has given an illustrated account of Moghuls' interests in conservation of nature, Alvi \& Rehman (Jahangir, The Naturalist. 1989. National Science Academy, New Delhi) has given a detail account of Jahangir's love for nature. Jahangir's observation on Sarus crane remains the oldest description on its breeding biology. Although Carl Linnaeus (1664) also mentioned some Indian birds in his system of Binomial nomenclature, the scientific documentation of Indian birds started with the invent of British.

India thus has a history of three centuries old ornithology. Several British Army, Medical and Civil Officers were keen naturalists and maintained well documentations of our flora and fauna. A. O. Hume (1888), the founder of Indian National Congress is also considered father of Indian Ornithology. The eleven volumes of journal Stray Feathers edited by him is landmark in documentation of Indian birds. Revised edition of Birds of Indian Empires in four volumes and three volumes of Nidification of Birds of Indian Empires 
by Sturats Baaker (1922 - 1930) are other very valuable publications. Based on Baker's, Salim Ali and Ripley (1964-1972) published ten volumes of Handbook of Birds of India and Pakistan that can be considered as the Bible of Indian Ornithology. Salim Ali's life and work has a remarkable influence on the conservation and propagation of avian study and due to his lifetime patronage birds became as Flagship of nature conservation movements in India. Although he supervised only a few disciples directly, he had a charismatic personality that influenced many including some leading politicians and officials of the country. Publication of his book, The Book of Indian Birds, first published in 1941 and $14^{\text {th }}$ enlarged and revised edition in 2006, remains a milestone for amateur bird watchers and students of ornithology. This book had great impact even on some politicians. Pandit Jawaharlal Nehru, the first Prime Minister of India, sent a copy of this book to his daughter Indira Gandhi on her $7^{\text {th }}$ birth day while he was imprisoned in Allahabad Jail. Consequently all three Prime Ministers of India from Nehru family had a great love for nature conservation.

Of late several useful field guides and text books relevant to Indian ornithology have also been published. However, despite a glorious past, due to gradual decline in the quality and content of most of the wildlife habitats, the future of India's wildlife, vis-à-vis birds, is far from secure. Environmental degradation, more notably the decline and fragmentation of forest cover in India is perhaps the most damaging factor for jeopardizing the sustainability of our faunal and floral heritage. Indiscriminate use of pesticides and insecticides and ineffective implementation of wildlife protection laws, and other anthropogenic pressures are adversely affecting the avifauna of the country. On a rough estimate, over hundred species of Indian birds are struggling under various categories of endangerment, while future of the rest is also insecure. While vultures' population has crashed alarmingly, and that too within a very short period of time, population of common birds like house sparrows, parakeets, baya weaver birds, etc, are also declining. Though reduction in birds' population is perhaps a global phenomenon, we need to discuss this issue more seriously as India's economy is largely based on agriculture and horticulture and birds play vital role in cleansing the insects and rodent pests from the field and orchards. The birds do damage the products to some extent at times, but in the words of Late Dr. Salim Ali this could be considered as 'laborer's hire'.

Despite the fact that during last 4 to 5 decades some good efforts have been taken to restore the Indian biodiversity vis-à-vis avian diversity, the developers and planners of the country need to incorporate avian conservation issues more effectively. In the post globalization development plan of India large tracts of natural habitats are being converted to agricultural and urban landscapes. The demographic and socio-economic factors in these areas have an adverse impact on the spatio-temporal dynamics of bird community and habitat. Hence biodiversity conservation in urban landscapes is also important. Because in the event of vanishing forests home gardens and parks can sustain and develop ecological complexity to the extent that they can provide necessary biodiversity and ecosystem services across the tropics. Further, the importance of urban parks within the cities is highlighted as hotspots for biodiversity. Park size accounts for the high indicators of species diversity but fragmentation is detrimental for the populations of resident bird species especially during breeding season. As increasing the park size within cities is not achievable, habitat diversity can be increased along with resource availability by adding nest boxes, bird feeders and bird baths to the parks. Wooded streets also contribute to avian diversity, however pedestrian disturbance is to be avoided in case of streets as well as parks. Increasing habitat heterogeneity by including chunks of open, bushy and closed vegetation along with an open bank water body also contributes to species diversity. Official policy making, research and awareness are other key factors.

In addition to various conservation measures prevailing in the country, we ought to emphasize the importance of education and awareness more elaborately and effectively. There is an urgent need to identify areas of gaps even in the regime of research and management of Indian birds. India being such a large country more coordinated efforts are needed for the proper management of any sector as well as for the conservation of our feathered friends. Several theoretical exercises, including preparation of National Biodiversity Action Plan (NBAP), cleaning of Ganges, Project tiger, etc, have so far not yielded desired results. In this respect role of key organizations such as BNHS Bombay, SACON Coimbatore, Wildlife Institute of India Dehradun, Department of Wildlife Sciences Aligarh, etc, become very vital. The Ministry Environment and Forest is doing good but much more efforts are needed to upkeep the balance of nature. Analytical scientific approach is needed to formulate policies to balance the country's development initiatives and nature conservation programs. Mad rush of unsustainable development may endanger both: biodiversity on which the mankind depends so heavily, and future of a healthy environment which is imperative for the survival of nature as well as the Homo sapiens. 